\title{
The relationship between dietary exposure to persistent organic pollutants from fish consumption and type 2 diabetes among First Nations in Canada
}

\author{
Lesya Marushka ${ }^{1} \cdot$ Xuefeng $\mathrm{Hu}^{2} \cdot$ Malek Batal $^{3,4} \cdot$ Constantine Tikhonov $^{1} \cdot$ Tonio Sadik $^{5} \cdot$ Harold Schwartz $^{1}$. \\ Amy Ing ${ }^{3} \cdot$ Karen Fediuk ${ }^{2} \cdot$ Hing Man Chan ${ }^{2}$ (D)
}

Received: 22 June 2020 / Accepted: 27 January 2021

(C) The Author(s) 2021

\begin{abstract}
Objective We previously examined the associations between dietary dichlorodiphenyldichloroethylene (DDE) and polychlorinated biphenyls (PCBs) intake from fish consumption and type 2 diabetes (T2D) prevalence in Ontario and Manitoba. This study aims to further explore the relationship in a regionally representative sample of First Nations adults living on-reserve across Canada.

Methods Dietary, health and lifestyle data collected by the cross-sectional First Nations Food, Nutrition and Environment Study (2008-2018) were analyzed. This participatory study included 6091 First Nations adult participants who answered questions on T2D. The consumption of locally caught fish was estimated with a food frequency questionnaire. A total of 551 samples from 96 fish species were collected and analyzed for the presence of DDE and PCBs. The associations between fish and dietary DDE/ PCBs intake with self-reported T2D were investigated using multiple logistic regression models adjusted for confounders.

Results Dietary exposure to DDE ( $>2.11 \mathrm{ng} / \mathrm{kg} / \mathrm{bw})$ and PCBs $(>1.47 \mathrm{ng} / \mathrm{kg} / \mathrm{bw})$ vs no exposure was positively associated with T2D with ORs of 2.33 (95\% CI: 1.24-4.35) for DDE and 1.43 (95\% CI: 1.01-3.59) for PCBs. The associations were stronger among females (DDE OR = 3.11 (1.41-6.88); PCBs OR = 1.76 (1.10-3.65)) and older individuals (DDE OR = 2.64 (1.12-6.20); PCBs OR = $1.44(1.01-3.91))$ as compared with males and younger participants. Also, significant dose-response relationships were found for fish consumption in females only.

Conclusion This study confirms our previous findings that dietary DDE/PCBs exposure may increase the risk of T2D. The effect of DDE/PCBs from fish consumption is driven by geographical differences in DDE/PCBs concentrations in fish and by the amount of fish consumed, and is more prominent in females than in males.
\end{abstract}

\section{Résumé}

Objectif Nous avons précédemment examiné les associations entre l'apport alimentaire de dichlorodiphényldichloroéthylène (DDE) et de polychlorobiphényles (PCB) provenant de la consommation de poisson et la prévalence du diabète de type 2 (DT2) en Ontario et au Manitoba. Cette étude vise à explorer davantage la relation dans un échantillon régionalement représentatif d'adultes des Premières Nations vivant dans des réserves partout au Canada.

Méthode Les données sur l'alimentation, la santé et le mode de vie recueillies par l'Étude transversale sur l'alimentation, la nutrition et l'environnement chez les Premières Nations (2008-2018) ont été analysées. Cette étude participative comprenait 6091 participants adultes des Premières Nations qui ont répondu à des questions sur le DT2. La consommation de poisson pêché

Hing Man Chan

laurie.chan@uottawa.ca

1 Environmental Public Health Division, First Nations and Inuit Health Branch, Indigenous Services Canada, Ottawa, ON, Canada

2 Department of Biology, University of Ottawa, 30 Marie Curie, Ottawa, ON K1N 6N5, Canada
3 Département de Nutrition, Faculté de Médecine, Pavillon Liliane de Stewart, Université de Montréal, C.P. 6128, succ. Centre-Ville, Montréal, QC H3T 1A8, Canada

4 Centre de recherche en santé publique de l'Université de Montréal et du CIUSS du Centre-sud-de-l'Île-de-Montréal (CReSP), 7101 avenue du Parc, Montréal, QC H3N 1X7, Canada

5 Assembly of First Nations, 55 Metcalfe Street, Suite 1600, Ottawa, ON K1P 6L5, Canada 
localement a été estimée à l'aide d'un questionnaire de fréquence alimentaire. Au total, 551 échantillons de 96 espèces de poissons ont été prélevés et analysés pour la présence de DDE et de PCB. Les associations entre la consommation de poisson et l'exposition aux DDE/PCB avec le DT2 auto-déclaré ont été étudiées à l'aide de modèles de régression logistique multiples ajustés pour les facteurs de confusion.

Résultats L'exposition alimentaire au DDE (>2,11 ng/kg/pc) et aux PCB (>1,47 ng/kg/pc) par rapport à l'absence d'exposition était positivement associée au DT2 avec des OR de 2,33 (IC à 95\% : 1,24-4,35) pour le DDE et 1,43 (IC à 95\%:1,01-3,59) pour les PCB. Les associations étaient plus fortes chez les femmes (DDE OR $=3,11(1,41-6,88)$; PCB OR $=1,76(1,10-3,65)$ ) et les individus plus âgés (DDE OR = 2,64 (1,12-6,20); PCB OR = 1,44 $(1,01-3,91)$ ) par rapport aux hommes et aux participants plus jeunes. De plus, des relations dose-réponse significatives ont été trouvées pour la consommation de poisson chez les femmes seulement.

Conclusion Cette étude confirme nos conclusions précédentes selon lesquelles l'exposition à travers l'alimentation aux DDE/ PCB peut augmenter le risque de DT2. L'effet du DDE/PCB sur la consommation de poisson est lié aux différences géographiques dans les concentrations de $\mathrm{DDE} / \mathrm{PCB}$ dans le poisson et à la quantité de poisson consommée, et est plus important chez les femmes que chez les hommes.

Keywords Dichlorodiphenyldichloroethylene (DDE) • Polychlorinated biphenyls (PCBs) · First Nations $\cdot$ Type 2 diabetes $\cdot$ Fish consumption

Mots-clés Dichlorodiphényldichloroéthylène (DDE) • polychlorobiphényles (PCB) · Premières Nations · diabète de type 2 . consommation de poisson

\section{Introduction}

Type 2 diabetes (T2D) has become increasingly prevalent among Indigenous populations (Acton et al. 2002; Crowshoe et al. 2018; Young et al. 2000). In Canada, First Nations are disproportionally affected by T2D and related complications compared with non-Indigenous population (Crowshoe et al. 2018; Young et al. 2000). Recent data indicate that, overall, $19.2 \%$ of First Nations adults (18+) living on-reserve have been diagnosed with diabetes (FNIGC 2018), varying from $10 \%$ to $26 \%$ across different regions of Canada (Batal et al. 2021a) compared with 7.3\% among the general Canadian population aged 12 and older (Statistics Canada 2018). T2D is a multifactorial disease caused by a complex interaction among environmental, socio-economic inequality, lifestyle and genetic factors. Lifestyle factors such as obesity, unhealthy diet and lack of physical activity are well-known risk factors for T2D (Day and Bailey 2011). Historically, the diet of First Nations was based on traditional foods harvested from the local environment and consisted of wild game, fish, plants and berries. This food contributes to both nutrient intake and physical fitness (Kuhnlein et al. 2004). Over the past decades, First Nations have been undergoing rapid lifestyle and dietary transitions, moving from a traditional highnutrient diet toward store-bought food, which is high in energy, fat and sugar (Kuhnlein et al. 2004). This dietary transition has been concomitant with a sedentary lifestyle, contributing to the high rates of obesity and T2D in the First Nations population (Batal and Decelles 2019; Young et al. 2000; JohnsonDown et al. 2015; Reeds et al. 2016).
Recently, exposure to environmental contaminants has been recognized as a new risk factor for T2D (Lee et al. 2018). Evidence from a number of epidemiological studies showed positive associations between exposure to persistent organic pollutants (POPs), such as dichlorodiphenyldichloroethylene (DDE) and polychlorinated biphenyls (PCBs), and T2D (Singh and Chan 2017; Wang et al. 2008; Wolf et al. 2019).

Recent evidence also suggests a potential link between mercury exposure and T2D (He et al. 2013). For example, high mercury levels $(>16 \mu \mathrm{g} / \mathrm{L})$ were associated with increased fasting glucose levels among Inuit living in Nunavik (Cordier et al. 2020).

POPs are lipophilic contaminants that persist in the environment and thus can be bioaccumulated and biomagnified along the aquatic food chain. This represents a serious concern for First Nations relying on these species for nutrition and for whom consumption of fish is essential to their cultural identity, spiritual health and overall well-being (Kuhnlein and Chan 2000). Indeed, fish and seafood are considered the main pathway of exposure to environmental contaminants, such as DDE, PCBs and mercury. Elevated exposure to POPs and mercury has been observed among First Nations consuming locally harvested fish and other traditional wildlife (Seabert et al. 2014).

On the other hand, fish consumption brings significant nutritional benefits contributing to the intake of high-quality protein, essential omega-3 fatty acids-namely, eicosapentaenoic acid (EPA) and docosahexaenoic acid (DHA) - and other nutrients (Ebbesson et al. 2005; Liaset et al. 2019). EPA-DHA intake has been shown to lower 
T2D risk by decreasing systemic inflammatory markers and circulating blood lipids and reducing insulin resistance (Fedor and Kelley 2009). Several prospective studies reported protective effects of fish consumption on T2D (Nanri et al. 2011; Villegas et al. 2011). However, systematic reviews and metaanalyses reported contradicting results on the associations among fish, EPA-DHA and T2D (Wu et al. 2012; Zhang et al. 2013; Zheng et al. 2012). The discrepancies between the findings on the associations between fish intake and T2D were explained by geographical differences in fish consumption patterns and POP levels in fish, which were not taken into account in the former studies (Lee and Jacobs 2010).

We previously investigated the associations among fish consumption, dietary EPA-DHA intake, and DDE and PCBs exposure with the prevalence of T2D in First Nations living on reserves in Manitoba and Ontario (Marushka et al. 2018; Marushka et al. 2017a; Marushka et al. 2017b). We found that dietary DDE/PCBs intake was positively associated with the prevalence of T2D, whereas fish (EPA-DHA) consumption showed protective associations with T2D. However, there was a regional difference; results were only significant in Ontario but not in Manitoba (Marushka et al. 2018). The relatively high dietary DDE/PCBs exposure from fish may outweigh protective associations of fish (EPA-DHA) on the prevalence of T2D (Marushka et al. 2018). Furthermore, we found gender differences in the association, with stronger positive associations between DDE/PCBs and T2D among females than among males. The objective of this study is to explore further the relationship between dietary DDE and PCBs intake and the prevalence of T2D among First Nations in Canada using an expanded dataset that is regionally representative of all on-reserve First Nations south of the $60^{\text {th }}$ parallel. We also aim to describe dietary DDE/PCBs exposure patterns at the ecozone level for risk management purposes.

\section{Methods}

\section{Study population}

This study analyzed data collected by the First Nations Food, Nutrition and Environment Study (FNFNES), a 10-year crosssectional participatory study (2008-2018) (Chan et al. 2021a). The FNFNES was designed to assess total diets, traditional food consumption patterns and food-related exposure to environmental contaminants in the First Nations adult population living on reserves south of the $60^{\text {th }}$ parallel across Canada in full partnership with the Assembly of First Nations and the participating communities. The selection of First Nations communities was performed using an ecozone framework comprised of 11 ecozones to represent the diversity of diets of First Nations. An ecozone is a large geographical region identified based on the distribution patterns of plants, animals, geographical characteristics and climate (ecozones.ca). The sampling was random and proceeded in three stages: the regions, the communities and the households. In each household, one adult self-identifying as a First Nation person living on-reserve and aged 19 years or older was invited to participate in the study. More details on the methodology are described elsewhere (Chan et al. 2019; Chan et al. 2021a). Sampling weights were calibrated for non-response and population change from 2008 to 2017 to obtain representative estimates of the total First Nations population south of the $60^{\text {th }}$ parallel in Canada. A set of 500 bootstrap weights were used to produce proper variance estimation.

Overall, 92 First Nations communities participated in the FNFNES. The participation process is described in Chan et al. (2021a). Information on diabetes was not collected in eight communities during the first year of the survey in British Columbia; therefore, the current study includes participants from a total of 84 First Nations communities across 10 Canadian ecozones (Batal et al. 2021a; Chan et al. 2011). The overall participation rate was $78 \%$. Pregnant and breastfeeding women who reported having unknown diabetes $(n=4)$ were excluded from the analyses to avoid potential misclassification of gestational diabetes. The final sample included 6085 participants aged 19 years and over.

\section{Ethics}

Ethics approvals were obtained from the Ethical Review Boards at Health Canada, the University of Northern British Columbia, the University of Ottawa and the Université de Montréal. In addition, the Assembly of First Nations (AFN) Chiefs-in-Assembly passed resolutions in support of this research. Participation in the study was voluntary. Written consent was obtained from each individual after an oral and written explanation of the project (Chan et al. 2021a).

\section{Data collection}

Dietary, socio-demographic, health and lifestyle data were collected using household interviews. Participants were asked to complete a social/health/lifestyle questionnaire (SHL), which collected information on age, gender, weight and height (measured or self-reported), physical activity, smoking status, years of education, household size, employment status, income source and dieting. The study participants were asked if a health care professional had ever told them that they had diabetes. If respondents answered affirmatively to the question, they were further asked about the type of diabetes they had (type 1, type 2, or unknown) and how many years ago they had been diagnosed. Only those participants who reported being diagnosed with T2D were included in this study. The questions on diabetes were only added in year 2 of the FNFNES, and information was not collected in the Boreal 
Cordillera. Therefore, results were reported in only 10 of 11 ecozones covered by FNFNES.

A traditional food frequency questionnaire (FFQ) was administrated to collect data on the consumption of locally caught traditional foods, including fish and seafood, during the four seasons in the past year (Batal et al. 2021b). The questionnaire was developed based on a comprehensive list of traditional foods that were representative of each participating community. Also, a 24-h dietary recall was completed to collect information on total diets (e.g., both traditional and store-bought foods over the prior 24 hours) (Chan et al. 2021a). Three-dimensional food and beverage models were used to estimate corresponding intake quantities. Age- and gender-specific portion sizes of each traditional food item were determined from the 24-h recall data (Chan et al. 2019).

Body mass index (BMI) was calculated as weight (in kilograms) divided by the square of height (in metres). BMI was calculated using both measured and/or reported heights and weights. Reported or a combination of reported and measured heights and weights were adjusted based on the measured ones (Chan et al. 2019). Based on BMI, all participants were categorized into three groups: normal weight (BMI $<25 \mathrm{~kg} / \mathrm{m}^{2}$ ), overweight (BMI 25-29.9 kg/m²) and obese (BMI $\geq 30 \mathrm{~kg} / \mathrm{m}^{2}$ ).

Physical activity data were self-reported. The study participants were asked to describe their physical activities as either inactive, somewhat active, moderately active or vigorous. For the purpose of this study, inactive and somewhat active physical activity categories were combined. To control for the potential contribution of mercury intake from fish consumption to $\mathrm{T} 2 \mathrm{D}$, we have included the mercury exposure as a covariate in the regression model.

\section{Fish sampling for contaminant analyses}

Fish samples collected for contaminant analyses were representative of all fish species consumed by members in each community as First Nations communities were asked to identify the most commonly consumed fish species and those that are of the most concern from an environmental perspective. Each fish sample was a composite of tissues from up to 5 different fish samples. The collected fish samples were analyzed for the presence of several environmental contaminants, including DDE, total PCBs and methylmercury ( $\mathrm{MeHg}$ ). More detailed information was published elsewhere (Chan et al. 2019; Chan et al. 2021b). Traditional foods collected in British Columbia and Manitoba were analyzed by Maxxam Analytics in Burnaby, British Columbia, while foods collected in other regions were analyzed by ALS Global in Burlington, Ontario (Chan et al. 2019; Chan et al. 2021b). All samples were homogenized to provide a homogeneous sample for subsequent digestion. If required, a moisture value was determined gravimetrically after drying a portion of the blended sample at $105^{\circ} \mathrm{C}$ overnight.

\section{DDE and PCBs}

Tissue (6 g) was homogenized in dichloromethane and filtered through anhydrous sodium sulphate. The extract was evaporated to $6 \mathrm{ml}$, and $5 \mathrm{ml}$ was injected onto the gel permeation chromatography column where a fraction of the eluent was collected, concentrated and solvent exchanged to acetone:hexane (1:1). Further clean-up was performed by eluting this extract through PSA (primary secondary amine) columns. The final extract was concentrated, and solvent exchanged to isooctane. Analysis was performed for DDE and PCBs using GC-MS in selective-ion monitoring mode with an electron ionization source. Spiked standards and blank samples were measured for quality analysis/quality control.

\section{Methylmercury}

Samples were prepared by alkaline digestion. A combination of methanol and potassium hydroxide was used to solubilize $\mathrm{MeHg}$ for instrumental analysis. Highly selective and sensitive detection was achieved by cold vapour atomic fluorescence spectrometry after the pyrolytic decomposition of the GC eluent. The diluted extract was buffered to a $\mathrm{pH}$ of 4.5-5.0 and treated with sodium tetraethylborate, resulting in the ethylation of oxidized mercury species. These volatile ethylated species (as well as elemental mercury) were stripped from the liquid phase with argon gas, retained on Tenaex traps, desorbed back into the sample stream and separated with a GC column. Each ethylated mercury species was released from the column en masse into the sample stream, thermally oxidized to elemental mercury and then detected by cold vapour atomic fluorescence spectrometry.

\section{Estimation of fish, DDE, PCBs, MeHg and EPA-DHA intake}

Fish intake (grams/day) was estimated by using both the FFQ and 24-h dietary recall data. Specifically, the total number of days over the past year when fish consumption was reported via the FFQ was multiplied by the age- and gender-specific portion size of fish species reported through the 24-h recalls (Marushka et al. 2017a). Total dietary DDE, PCBs and MeHg intakes were estimated for each individual as follows: the amount of DDE and PCBs (in nanograms/gram), and $\mathrm{MeHg}$ (in micrograms/gram) in each fish species was multiplied by the total amount $(\mathrm{g})$ of each fish species consumed per day; then, DDE, PCBs and MeHg intake from all fish species eaten per day were summed up and divided by the body weight of each participant (e.g., ng/kg bw/day for DDE, PCBs and $\mu \mathrm{g} / \mathrm{kg}$ bw/day for $\mathrm{MeHg}$ ). Community-specific data on DDE, PCBs and $\mathrm{MeHg}$ concentrations in fish species were used to estimate dietary contaminant exposure. If the community-specific concentrations were not available, ecozone-specific data were applied. If neither community 
nor ecozone-based DDE, $\mathrm{PCBs}$ and $\mathrm{MeHg}$ concentrations were available for a fish species, regional or national average contaminant data were calculated. Dietary assessments were validated through correlation analyses between $\mathrm{MeHg}$ intake from traditional foods estimated with the FFQ and mercury concentrations in hair measured in First Nations participants (Tikhonov et al. 2021). Dietary mercury intake was correlated with mercury levels in hair.

The concentrations of EPA and DHA in fish species were derived from the Canadian Nutrient File and captured cooking method (Health Canada 2015). In this analysis, EPA-DHA intake combines the amount of EPA and DHA consumed from fish and is expressed as g/day.

\section{Statistical analysis}

Descriptive statistics include the calculation of proportions for categorical variables, means with standard deviation (SD) and medians with interquartile range for continuous variables. Student $t$ tests, analysis of variance (ANOVA) and chi-square tests were applied to test statistical significance between subgroups. Subgroup-stratified statistics by ecozone $(n=10)$ were calculated to describe fish consumption patterns and dietary DDE and PCBs intake. Fish consumption was divided into four categories: no fish, $<10 \mathrm{~g} /$ day, $10-20 \mathrm{~g} /$ day, and $>20 \mathrm{~g} /$ day. Dietary DDE and PCBs intake were categorized into three groups according to the thresholds for the effects of daily dietary DDE, and PCBs intake on the prevalence of T2D (e.g., breakpoints for DDE and PCBs) estimated in our previous study and published elsewhere (Marushka et al. 2018):

(1) no exposure,

(2) $<2.11 \mathrm{ng} / \mathrm{kg}$ bw (<breakpoint for DDE) and $<1.47$ $\mathrm{ng} / \mathrm{kg}$ bw (<breakpoint for PCBs), and

(3) $\geq 2.11 \mathrm{ng} / \mathrm{kg}$ bw (>breakpoint for DDE) and $\geq 1.47$ $\mathrm{ng} / \mathrm{kg}$ bw (>breakpoint for PCBs).

Multiple logistic regression models adjusted for confounding factors were fitted to examine the associations between fish consumption and dietary PCBs and DDE intake categories, individually, with $\mathrm{T} 2 \mathrm{D}$. The following potential confounding factors were considered: age, gender, BMI, physical activity (inactive/sedentary, moderate, and vigorous), smoking status (yes and no), energy intake, dieting status (yes and no), food security status (food secure, moderately food insecure, and severely food insecure), years of education, household size, income source (wage, social assistance, and pension), employment status (yes and no), $\mathrm{MeHg}$ and EPADHA intake, ecozone (Pacific Maritime, Montane Cordillera, Taiga Plains, Boreal Plains, Prairies, Boreal Shield, Taiga Shield, Hudson Plains, Mixedwood Plains and Atlantic Maritime) and region (British Columbia, Alberta, Saskatchewan, Manitoba, Ontario, Quebec and Labrador, and the Atlantic region which combines Nova Scotia, New Brunswick, Prince Edward Island and Newfoundland).

Control variables were added into the models gradually to see the relative contribution of other risk factors and their influence on the magnitudes of the effect. The final models included the following covariates: age, gender, BMI, energy intake, dieting status, physical activity, smoking status, region, ecozone, years of education, household size, income source and employment status, and estimated dietary intake of PCBs or DDE, MeHg and EPA-DHA.

Multiple logistic regression analyses were developed for the total population and subgroups (age groups $(<45$ years; $\geq 45$ years) and gender). We chose the age of 45 as the cutoff between the groups since it was close to the median age of the study population across different regions of Canada. Variables that did not fit a normal distribution were normalized using the natural logarithmic function (e.g., DDE, PCBs, $\mathrm{MeHg}$ and EPA-DHA). Dietary contaminant levels below the limit of detection (LOD) were imputed with half of LOD of PCBs $(0.0003 \mu \mathrm{g} / \mathrm{g})$, DDE $(0.0005 \mu \mathrm{g} / \mathrm{g})$ and $\mathrm{MeHg}(0.004$ $\mu \mathrm{g} / \mathrm{g}$ ) to avoid errors in the analysis (Chan et al. 2019).

Results with a $p$ value of less than 0.05 were considered statistically significant. STATA statistical software 14.2 (StataCorp, College Station, TX, USA) was used to perform all statistical analyses.

\section{Results}

This study included a total of 6085 First Nations participants with available self-reported data on diabetes. Among them, $4883(80 \%)$ reported never to have been diagnosed with diabetes, 136 reported to have been diagnosed with type 1 diabetes, 855 reported having been diagnosed with T2D, and 211 reported "unknown type" of diabetes. Among those with "unknown type" of diabetes, 203 had characteristics of T2D (being overweight or obese, being age 40 years or older at the onset of diabetes, and having an inactive or sedentary lifestyle) and were categorized as T2D for these analyses. Individuals with type 1 diabetes were categorized as without T2D. Therefore, in total, 1058 participants were categorized as with T2D, and 5027 participants were categorized as without T2D (Table 1). The adjusted prevalence of self-reported T2D in the total First Nations population was $18.8 \%$ and was similar in females (18.7\%) and males (18.9\%). The mean BMI was $30.8 \mathrm{~kg} / \mathrm{m}^{2}$ and was comparable between females $\left(31.2 \mathrm{~kg} / \mathrm{m}^{2}\right)$ and males $\left(30.1 \mathrm{~kg} / \mathrm{m}^{2}\right)$. Individuals with T2D were more likely to be older, to have a higher BMI, to be less physically active, and to have lower educational attainment than those without T2D. Smoking was reported by 53\% of the study population and was significantly lower among participants with T2D (45.6\% vs. 55.4\%). Individuals diagnosed 
Table 1 Descriptive characteristics of FNFNES participants who had data on selfreported T2D $(n=6091)$

\begin{tabular}{|c|c|c|c|c|c|}
\hline & \multicolumn{2}{|c|}{ Without T2D } & \multicolumn{3}{|c|}{ With T2D } \\
\hline & $\begin{array}{l}\text { Mean/ } \\
\%\end{array}$ & $95 \% \mathrm{CI} / n$ & $\begin{array}{l}\text { Mean/ } \\
\%\end{array}$ & $95 \% \mathrm{CI} / n$ & $p$ value \\
\hline$n$ & 81.2 & 5027 & 18.8 & 1058 & \\
\hline Age, years & 42.4 & $41.2-43.5$ & 53.7 & $52.3-55.0$ & 0.001 \\
\hline Female & 67.8 & 3308 & 67.8 & 712 & 0.98 \\
\hline BMI, $\mathrm{kg} / \mathrm{m}^{2}$ & 30.2 & $29.7-30.7$ & 33.4 & $32.3-34.5$ & 0.001 \\
\hline Physical activity & & & & & 0.001 \\
\hline Inactive/sedentary & 61.6 & 3135 & 73.4 & 773 & \\
\hline Moderate & 27.8 & 1332 & 19.7 & 217 & \\
\hline Vigorous & 10.6 & 562 & 6.9 & 66 & \\
\hline Smoking & 55.4 & 2800 & 45.6 & 485 & 0.006 \\
\hline Dieting & 9.8 & 490 & 12.5 & 138 & 0.107 \\
\hline Years of education & 10.9 & $10.6-11.1$ & 10.2 & $9.8-10.6$ & 0.001 \\
\hline Household size, $n$ & 4.8 & $4.6-5$ & 4.8 & $4.3-5.3$ & 0.89 \\
\hline Employment, any & 71.7 & 3317 & 67.4 & 608.0 & 0.10 \\
\hline Income source & & & & & 0.001 \\
\hline Wage & 57.0 & 2724 & 48.1 & 453 & \\
\hline Social assistance & 34.8 & 1826 & 29.1 & 320 & \\
\hline Pension & 8.2 & 478 & 22.8 & 284 & \\
\hline Energy intake, kcal & 1998 & $1921-2076$ & 1801 & $1690-1911$ & 0.008 \\
\hline Fish consumers & 65.2 & 3501 & 75.4 & 819 & 0.001 \\
\hline Fish intake, g/day & 13.2 & $9.6-16.7$ & 18.5 & $12.0-25.1$ & 0.057 \\
\hline DDE, ng/kg bw/day & 0.38 & $0.25-0.51$ & 0.60 & $0.35-0.85$ & 0.03 \\
\hline PCBs, ng/kg bw/day & 0.76 & $0.52-1.00$ & 1.63 & $0.82-2.43$ & 0.02 \\
\hline EPA-DHA, g/day & 0.12 & $0.08-0.16$ & 0.15 & $0.09-0.21$ & 0.18 \\
\hline $\mathrm{MeHg}, \mu \mathrm{g} / \mathrm{kg}$ bw/day & 0.11 & $0.07-0.15$ & 0.26 & $0.10-0.61$ & 0.39 \\
\hline
\end{tabular}

$T 2 D$, type 2 diabetes; $B M I$, body mass index

The age-standardized prevalence of T2D was $21.3 \%$ (based on the 2016 Canadian census data)

Employment, any, either full- or part-time employment

$D D E$, dichlorodiphenyldichloroethylene; $P C B s$, polychlorinated biphenyls; $E P A$, eicosapentaenoic acid; $D H A$, docosahexaenoic acid, $\mathrm{MeHg}$, methylmercury

$p$ values correspond to $t$ tests for continuous variables and chi-square tests for categorical variables

Weighted estimates with T2D reported significantly lower energy intake (1800 kcal vs $1998 \mathrm{kcal})$.

Overall, $67.1 \%$ of First Nations participants reported consuming traditionally caught fish at least once in the prior year with an average daily intake of $14.9 \mathrm{~g} /$ day. Individuals with $\mathrm{T} 2 \mathrm{D}$ ate more fish $(18.5 \mathrm{~g} /$ day $)$ than those without T2D (13.2 g/day). Similarly, dietary DDE and PCBs intake was higher in diabetic (DDE $0.60 \mathrm{ng} / \mathrm{kg} \mathrm{bw} / \mathrm{day}$; PCBs $1.63 \mathrm{ng} / \mathrm{kg}$ bw/day) than in non-diabetic (DDE $0.38 \mathrm{ng} / \mathrm{kg}$ bw/day; PCBs 0.76 $\mathrm{ng} / \mathrm{kg}$ bw/day) individuals.

Table 2 summarizes the characteristics of the study participants by dietary DDE and PCBs exposure. The DDE/PCBs intake was categorized based on the breakpoint values for DDE $(2.11 \mathrm{ng} / \mathrm{kg}$ bw/day) and PCBs $(1.47 \mathrm{ng} / \mathrm{kg}$ bw/day) we estimated previously (Marushka et al. 2018). Overall, intake of DDE and PCBs was associated with higher fish consumption, higher EPA-DHA intake and $\mathrm{MeHg}$ exposure, higher prevalence of T2D, older age, being male, and smaller household size. The BMI, total energy intake, physical activity, education level, and income sources were not different between the DDE/PCBs exposure groups.

Multiple logistic regression analyses of the associations between dietary DDE and PCBs exposure and T2D are presented in Table 3. Model 1 was controlled for age, gender, BMI, physical activity, smoking and region. Model 2 was additionally adjusted for total energy intake, education level, household size, income source and employment status. Model 3 was further controlled for log-transformed DDE or PCBs, respectively, along with dietary $\mathrm{MeHg}$ and $\mathrm{EPA}+\mathrm{DHA}$ intake. 
Table 2 Characteristics of FNFNES participants by dietary DDE and PCBs exposure categories

\begin{tabular}{|c|c|c|c|c|c|c|c|c|}
\hline & \multicolumn{4}{|l|}{ DDE } & \multicolumn{4}{|l|}{$\mathrm{PCBs}$} \\
\hline & No exposure & $<2.11 \mathrm{ng} / \mathrm{kg}$ bw & $\geq 2.11 \mathrm{ng} / \mathrm{kg}$ bw & $\begin{array}{l}p \\
\text { trend }\end{array}$ & No exposure & $<1.47 \mathrm{ng} / \mathrm{kg}$ bw & $\geq 1.47 \mathrm{ng} / \mathrm{kg}$ bw & $\begin{array}{l}p \\
\text { trend }\end{array}$ \\
\hline$n$ & 1769 & 3971 & 345 & & 1769 & 3656 & 660 & \\
\hline Fish intake, g/day & 0 & $13.8(11-16.7)$ & $\begin{array}{l}119.1 \\
\quad(99.8-138.4)\end{array}$ & 0.000 & 0 & $14.5(11.2-17.9)$ & $54.5(37.2-71.8)$ & 0.000 \\
\hline DDE, ng/kg bw/day & 0 & $0.27(0.22-0.32)$ & $5.40(4.34-6.45)$ & 0.000 & 0 & $0.27(0.2-0.33)$ & $2.44(1.72-3.16)$ & 0.000 \\
\hline PCBs, ng/kg bw/day & 0 & $0.78(0.56-1)$ & $\begin{array}{l}9.39 \\
\quad(5.01-13.77)\end{array}$ & 0.000 & 0 & $0.22(0.19-0.26)$ & $7.26(5.72-8.8)$ & 0.000 \\
\hline EPA-DHA, g/day & 0 & $0.10(0.08-0.13)$ & $1.31(1.07-1.54)$ & 0.000 & 0 & $0.13(0.1-0.16)$ & $0.49(0.29-0.68)$ & 0.000 \\
\hline $\mathrm{MeHg}, \mu \mathrm{g} / \mathrm{kg}$ bw/day & 0 & $0.11(0.06-0.17)$ & $\begin{array}{l}1.42 \\
\quad(-0.17-3.01)\end{array}$ & 0.000 & 0 & $0.12(0.06-0.18)$ & $0.64(0.07-1.2)$ & 0.000 \\
\hline $\mathrm{T} 2 \mathrm{D}, \%$ & 14.1 & 20.7 & 26.6 & 0.001 & 14.1 & 19.7 & 28.4 & 0.001 \\
\hline Age, years & $42(40.4-43.6)$ & $45.4(44.3-46.5)$ & $50.8(47.7-54)$ & 0.001 & $42(40.4-43.6)$ & $45(43.9-46.1)$ & $49.8(48.0-51.6)$ & 0.001 \\
\hline Female, $\%$ & 72.6 & 66.3 & 54.1 & 0.007 & 72.6 & 68 & 52.7 & 0.003 \\
\hline BMI, $\mathrm{kg} / \mathrm{m}^{2}$ & $30.1(29.5-30.7)$ & $31.3(30.6-31.9)$ & $29.9(28-31.9)$ & 0.06 & $30.1(29.5-30.7)$ & $31.1(30.6-31.6)$ & $31.5(29.9-33.2)$ & 0.038 \\
\hline Energy intake, kcal & $\begin{array}{l}1928 \\
\quad(1836-2020)\end{array}$ & $\begin{array}{l}1970 \\
\quad(1895-2045)\end{array}$ & $\begin{array}{l}2062 \\
\quad(1878-2245)\end{array}$ & 0.15 & $\begin{array}{l}1928 \\
\quad(1836-2020)\end{array}$ & $\begin{array}{l}1948 \\
\quad(1861-2036)\end{array}$ & $\begin{array}{l}2120 \\
\quad(1987-2253)\end{array}$ & 0.02 \\
\hline Physical inactivity & 63.1 & 65.2 & 49.6 & 0.73 & 63.1 & 64.5 & 62.2 & 0.96 \\
\hline Smoking, $\%$ & 58.4 & 51.8 & 42.9 & 0.001 & 58.4 & 51.3 & 50.4 & 0.002 \\
\hline Dieting, \% & 9.1 & 10.4 & 17.7 & 0.04 & 9.1 & 10.7 & 12.0 & 0.12 \\
\hline Education, years & $11(10.6-11.3)$ & $10.6(10.3-11)$ & $10.8(10.2-11.5)$ & 0.30 & $11(10.6-11.3)$ & $10.7(10.4-11)$ & $10.4(9.2-11.7)$ & 0.30 \\
\hline Household size, $n$ & $5.1(4.8-5.4)$ & $4.7(4.4-5.1)$ & $3.7(3.3-4.1)$ & 0.001 & $5.1(4.8-5.4)$ & $4.7(4.4-5.1)$ & $4.4(4.0-4.8)$ & 0.001 \\
\hline Employment, \% & 68.7 & 71.6 & 75.7 & 0.09 & 68.7 & 71.4 & 74.6 & 0.23 \\
\hline Income source, $\%$ & & & & 0.20 & & & & 0.24 \\
\hline Wage & 52.9 & 56.8 & 52.6 & & 52.9 & 56.5 & 56.4 & \\
\hline Social assistance & 39.5 & 31.2 & 26.4 & & 39.5 & 32.1 & 24.6 & \\
\hline Pension & 7.6 & 12.0 & 21.0 & & 7.6 & 11.4 & 19.0 & \\
\hline
\end{tabular}

Values are mean $(95 \% \mathrm{CI})$ or percentage $(\%)$, weighted estimates

$T 2 D$, type 2 diabetes; $B M I$, body mass index; $D D E$, dichlorodiphenyldichloroethylene; $P C B s$, polychlorinated biphenyls; $E P A$, eicosapentaenoic acid; $D H A$, docosahexaenoic acid, $\mathrm{MeHg}$, methylmercury

Physical inactivity combines self-reported inactive and sedentary lifestyle

For the total population, significant positive associations were found between DDE and PCBs with T2D across all models. The associations were stronger for DDE than for PCBs, and in the models further adjusted for MeHg and EPA-DHA intake. The adjusted odds ratios (ORs) for DDE intake of less than $2.11 \mathrm{ng} / \mathrm{kg} \mathrm{bw/day}$ was 1.28 (95\% CI: $0.98-1.64$ ), and for exposure to $\geq 2.11 \mathrm{ng} / \mathrm{kg}$ bw/day of DDE was 2.33 (95\% CI: 1.24-4.35). The corresponding ORs for PCBs intake of $<1.47 \mathrm{ng} / \mathrm{kg}$ bw/day was 1.30 (95\% CI: $0.97-$ 1.75 ) and the exposure to $\geq 1.47$ of PCBs was 1.43 (95\% CI: $1.01-3.59$ ).

In the gender-based stratified analyses, the positive effects of DDE and PCBs on the prevalence of T2D were observed in females only across all models. In the fully adjusted model, the exposure to $\geq 2.11 \mathrm{ng} / \mathrm{kg}$ bw/day of DDE resulted in about a 3-times increase in the prevalence of T2D $(\mathrm{OR}=3.11$ (95\% CI: 1.41-6.88)) compared with the reference group.
The exposure to PCBs at the level of $\geq 1.47 \mathrm{ng} / \mathrm{kg}$ bw/day increased the odds of T2D by about 1.8 times compared with no exposure (OR $=1.76$ (95\% CI: $1.10-3.65)$ ).

Effect estimates of DDE and PCBs were also examined in the fully adjusted models stratified by age groups. Among individuals aged 19-44 years, the associations between DDE (OR $=2.12$ (95\% CI: 0.42-9.77)) and PCBs (OR $=2.13$ (95\% CI: 0.46-9.77)) with T2D were positive but not statistically significant. Among individuals aged 45 years and over, the exposure to DDE at the threshold level of $\geq 2.11 \mathrm{ng} / \mathrm{kg} \mathrm{bw} /$ day resulted in a 2.6 -fold increase in the prevalence of T2D compared with the reference group $(\mathrm{OR}=2.64$ (95\% CI: 1.12-6.20)). Similarly, the exposure to PCBs at the threshold level of $\geq 1.47 \mathrm{ng} / \mathrm{kg}$ bw/day resulted in a 1.4-times increase in the prevalence of T2D compared with the reference (no exposure) category ( $\mathrm{OR}=1.44$ (95\% CI:1.01-3.91)). However, the exposure to lower 
Table 3 Multiple logistic regression analyses of dietary DDE and PCBs exposure and type 2 diabetes

DDE

\begin{tabular}{lll}
\hline No exposure & $<2.11 \mathrm{ng} / \mathrm{kg}$ bw & $\geq 2.11 \mathrm{ng} / \mathrm{kg}$ bw \\
Reference & OR $(95 \% \mathrm{CI})$ & OR $(95 \% \mathrm{CI})$
\end{tabular}

Total population

Model $1 \quad 1.0$

Model $2 \quad 1.0$

Model $3 \quad 1.0$

Females

Model $1 \quad 1.0$

Model $2 \quad 1.0$

Model $3 \quad 1.0$

Males

Model $1 \quad 1.0$

Model $2 \quad 1.0$

Model $3 \quad 1.0$

Aged $<45$ y

Model $1 \quad 1.0$

Model $2 \quad 1.0$

Model $3 \quad 1.0$

Aged $\geq 45$ y

Model $1 \quad 1.0$

Model 2

Model 3

1.0

1.0

$1.28 *(0.98-1.67)$
$1.26 *(0.97-1.65)$
$1.28 *(0.98-1.64)$
$1.49 * *(1.07-2.07)$
$1.50 * *(1.06-2.09)$
$1.65 * * *(1.18-2.31)$
$0.91(0.76-1.38)$
$0.89(0.73-1.33)$
$0.99 *(0.69-1.73)$
$1.36(0.85-2.17)$
$1.38(0.84-2.26)$
$1.49(0.80-2.77)$
$1.22(0.92-1.59)$
$1.18(0.89-1.54)$
$1.28(0.76-2.17)$

$2.14 * *(1.18-3.85)$

$2.27 * * *(1.27-4.01)$

$2.33^{* * *}(1.24-4.35)$

$2.25 * *(1.15-4.40)$

$2.29 * *(1.16-4.51)$

$3.11^{* * *}(1.41-6.88)$

$1.59(0.89-3.92)$

$1.77(0.92-4.36)$

$1.89(0.88-6.81)$

$1.80(0.52-7.76)$

$1.82(0.42-7.90)$

$2.12(0.42-9.77)$

$2.22 * *(1.17-4.17)$

$2.29 * * *(1.22-4.26)$

$2.64 * * *(1.12-6.20)$

PCBs

\begin{tabular}{lll}
\hline $\begin{array}{l}\text { No exposure } \\
\text { Reference }\end{array}$ & $<1.47 \mathrm{ng} / \mathrm{kg} \mathrm{bw}$ & $\geq 1.47 \mathrm{ng} / \mathrm{kg} \mathrm{bw}$ \\
& OR $(95 \% \mathrm{CI})$ & OR $(95 \% \mathrm{CI})$
\end{tabular}

1.0

1.0

1.0

1.0

1.0

1.0

1.0

1.0

1.0

1.0

1.0

1.0

1.0

1.0

1.0

$\begin{array}{ll}1.29(0.93-1.81) & 1.42^{*}(0.91-1.81) \\ 1.27(0.91-2.01) & 1.40^{* *}(1.01-3.50) \\ 1.30(0.97-1.75) & 1.43^{* *}(1.01-3.59) \\ & \\ 1.49^{* *(1.06-2.12)} & 1.69^{* *}(1.10-2.60) \\ 1.43^{* *(1.03-2.00)} & 1.75^{* *}(1.12-2.71) \\ 1.44 * *(1.01-2.31) & 1.76^{* *}(1.10-3.65) \\ 0.89(0.57-1.39) & 1.16(0.35-3.86) \\ 0.86(0.53-1.39) & 1.20(0.43-3.99) \\ 0.89(0.55-1.42) & 1.22(0.40-5.63) \\ & \\ 1.36(0.85-2.17) & 1.80(0.48-7.73) \\ 1.37(0.84-2.25) & 1.81(0.46-7.80) \\ 1.49(0.80-2.77) & 2.13(0.46-9.77) \\ & \\ 1.22(0.83-1.71) & 1.43(0.88-3.04) \\ 1.19(0.84-1.68) & 1.38^{*}(0.96-3.88) \\ 1.22(0.89-1.67) & 1.44 * *(1.01-3.91)\end{array}$

$1.29(0.93-1.81)$

$.42 *(0.91-1.81)$

$.40 * *(1.01-3.50)$

$.69 * *(1.10-2.60)$

$1.75 * *(1.12-2.71)$

$16(0.35-3.86)$

$1.20(0.43-3.99)$

$1.22(0.40-5.63)$

$81(0.46-7.80)$

$2.13(0.46-9.77)$

$1.38 *(0.96-3.88)$

$.44 * *(1.01-3.91)$

${ }^{*} p<0.1,{ }^{* *} p<0.05,{ }^{* * *} p<0.01 ; O R$, odds ratio

$2.11 \mathrm{ng} / \mathrm{kg}$ bw/day and $1.47 \mathrm{ng} / \mathrm{kg}$ bw/day are breakpoints for dietary DDE and PCBs intake, respectively (see Marushka et al. (2018) for more details)

Model 1: adjusted for age, gender, body mass index, physical activity, smoking, ecozone and region

Model 2: model 1 additionally adjusted for energy intake, dieting status, years of education, household size, income source and employment status

Model 3: model 2 additionally adjusted for log-transformed DDE or PCBs, respectively, as well as MeHg and EPA+DHA

$D D E$, dichlorodiphenyldichloroethylene; $P C B s$, polychlorinated biphenyls; $E P A$, eicosapentaenoic acid; $D H A$, docosahexaenoic acid; $M e H g$, methylmercury

doses of DDE/PCBs was not statistically significantly associated with T2D among older individuals.

Table 4 presents characteristics of the study population by four fish consumption categories (no fish, $<10 \mathrm{~g} /$ day, 10-20 g/day, and $>20 \mathrm{~g} /$ day). Higher fish consumption was associated with older age, being male, higher prevalence of self-reported T2D, dieting and being employed. However, the prevalence of smoking and household size were higher among those who consumed less fish. The BMI, level of physical activity, total energy intake and years of education were comparable among participants across the four fish consumption groups.

The multiple logistic regression analyses on the association between fish consumption and T2D are presented in Table 5. Model 1 was adjusted for age, gender, BMI and region. Model 2 was further adjusted for physical activity, smoking, energy intake, dieting status, education level, household size, income source and employment status. Analyses for the total population showed dose-response relationships across all fish consumption categories with the prevalence of T2D with OR of $1.46(95 \% \mathrm{CI}$ : $0.99-2.15)$ for $10-20 \mathrm{~g}$ of daily fish intake and OR of 1.78 (95\% CI: 1.20-2.66) for the intake of over $20 \mathrm{~g} /$ day of fish when compared with no fish consumption.
In stratified by gender analyses, the associations between fish intake and T2D were statistically significant in females but not in males. In females, the fully adjusted OR for the highest ( $>20 \mathrm{~g} /$ day) vs the reference (no fish intake) category was 2.08 (95\% CI: 1.31-3.31), whereas in males, the respective OR was 1.25 (95\% CI: $0.63-2.48$ ). In the analyses stratified by age groups ( $<45$ years vs $\geq 45$ years), consumption of more than $20 \mathrm{~g} /$ day of fish vs no fish intake was positively associated with T2D in both groups, with OR of 2.65 (95\% CI: 1.01-6.96) in younger individuals and OR of $1.48(95 \%$ CI: 1.01-2.15) in the older age group.

Table 6 in the Appendix summarizes data on the proportion of fish consumers, daily fish consumption, as well as the average dietary DDE/PCBs intake across 10 Canadian ecozones: the Pacific Maritime, Montane Cordillera, Taiga Plains, Boreal Plains, Prairies, Boreal Shield, Taiga Shield, Hudson Plains, Mixedwood Plains and Atlantic Maritime (Fig. 1). Overall, fish consumption was reported by $67.1 \%$ of First Nations participants, while ranging from $41.8 \%$ to $97.2 \%$ across ecozones. The highest fish consumption was reported by First Nations living in the Pacific Maritime ecozone with a mean intake of $76.5 \mathrm{~g} /$ day (median $45.4 \mathrm{~g} /$ day) followed by 
Table 4 Characteristics of FNFNES participants by fish consumption categories

\begin{tabular}{|c|c|c|c|c|c|}
\hline & No fish & $<10 \mathrm{~g} /$ day & $10-20 \mathrm{~g} /$ day & $>20 \mathrm{~g} /$ day & $p$ trend \\
\hline$n$ & 1769 & 2537 & 628 & 1151 & \\
\hline Fish intake, g/day & 0 & $3.3(3.0-3.6)$ & $14.0(13.5-14.5)$ & $68.6(60.5-76.8)$ & 0.000 \\
\hline DDE, ng/kg bw/day & 0 & $0.10(0.08-0.12)$ & $0.43(0.33-0.52)$ & $2.01(1.46-2.56)$ & 0.000 \\
\hline PCBs, ng/kg bw/day & 0 & $0.41(0.31-0.50)$ & $1.52(0.92-2.11)$ & $3.36(2.01-4.70)$ & 0.000 \\
\hline EPA-DHA, g/day & 0 & $0.02(0.019-0.03)$ & $0.10(0.09-0.12)$ & $0.65(0.54-0.77)$ & 0.000 \\
\hline $\mathrm{MeHg}, \mu \mathrm{g} / \mathrm{kg}$ bw/day & 0 & $0.09(0.01-0.17)$ & $0.20(0.03-0.38)$ & $0.54(0.11-0.96)$ & 0.000 \\
\hline $\mathrm{T} 2 \mathrm{D}, \%$ & 14.1 & 19.2 & 23.7 & 24.3 & 0.002 \\
\hline Age, years & $42.0(40.4-43.6)$ & $44.8(43.6-45.9)$ & $46.5(44.5-48.5)$ & $47.8(45.8-49.7)$ & 0.000 \\
\hline Female, $\%$ & 72.6 & 71.2 & 58.0 & 56.4 & 0.000 \\
\hline BMI, $\mathrm{kg} / \mathrm{m}^{2}$ & $30.1(29.5-30.7)$ & $31.1(30.6-31.6)$ & $31.9(30.4-33.4)$ & $31.0(29.9-32.0)$ & 0.12 \\
\hline Energy intake, kcal & 1928(1835-2020) & $1969(1880-2060)$ & $1925(1835-2015)$ & $2020(1895-2145)$ & 0.18 \\
\hline Physical inactivity, \% & 63.1 & 65.1 & 70.5 & 58.9 & 0.37 \\
\hline Smoking, $\%$ & 58.4 & 53.3 & 51.4 & 46.2 & 0.001 \\
\hline Dieting, \% & 9.1 & 9.2 & 11.1 & 14.5 & 0.002 \\
\hline Years of education & $11.0(10.6-11.3)$ & $10.7(10.5-11.0)$ & $10.4(9.8-11.0)$ & $10.6(9.9-11.3)$ & 0.4 \\
\hline Household size, $n$ & $5.1(4.8-5.4)$ & $4.8(4.4-5.1)$ & $4.4(3.9-5.0)$ & $4.5(3.9-5.1)$ & 0.01 \\
\hline Employment, any, \% & 68.7 & 70.2 & 71.2 & 76.0 & 0.009 \\
\hline Income source, $\%$ & & & & & 0.28 \\
\hline Wage & 52.9 & 56.4 & 57.6 & 56.2 & \\
\hline Social assistance & 39.5 & 32.9 & 26.8 & 28.6 & \\
\hline Pension & 7.6 & 10.8 & 15.6 & 15.2 & \\
\hline
\end{tabular}

Values are mean $(95 \% \mathrm{CI})$ or percentage $(\%)$, weighted estimates

$T 2 D$, type 2 diabetes; $B M I$, body mass index; $D D E$, dichlorodiphenyldichloroethylene; $P C B s$, polychlorinated biphenyls; $E P A$, eicosapentaenoic acid; $\mathrm{DHA}$, docosahexaenoic acid; $\mathrm{MeHg}$, methylmercury

Physical inactivity combines self-reported inactive and sedentary lifestyle

$30.0 \mathrm{~g} /$ day (median $8.7 \mathrm{~g} /$ day) in the Montane Cordillera, 22.6 $\mathrm{g} /$ day (median $8.9 \mathrm{~g} /$ day) in the Taiga Shield and $22.6 \mathrm{~g} /$ day (median $6.6 \mathrm{~g} /$ day) in the Boreal Shield. The lowest fish consumption was observed in the Prairies ecozone (3.6 g/day). Dietary DDE and PCBs exposure significantly varied across ecozones. For instance, the highest DDE intake was seen in the Pacific Maritime ecozone with a mean intake of 2.01 $\mathrm{ng} / \mathrm{kg}$ bw/day (median $1.21 \mathrm{ng} / \mathrm{kg}$ bw/day), where almost $30 \%$ of participants exceeded the threshold for DDE intake (e.g., $2.11 \mathrm{ng} / \mathrm{kg}$ bw/day). On the other hand, the highest dietary exposure to PCBs was observed in the Hudson Plains ecozone with a mean intake of $2.61 \mathrm{ng} / \mathrm{kg}$ bw/day and over $23 \%$ of respondents with dietary PCBs intake exceeding the breakpoint of $1.47 \mathrm{ng} / \mathrm{kg}$ bw/day. The exposure to PCBs was also notably higher in the Mixedwood Plains, Boreal Shield and Taiga Shield ecozones, with 20\%, 18.7\% and $18 \%$ of participants, respectively, exceeding the breakpoint of PCBs (Table 6 in the Appendix).

\section{Discussion}

The findings of this study were similar to our earlier study, i.e., that dietary DDE and PCBs exposure is positively associated with the prevalence of T2D in the overall population. Exposure to the DDE threshold level and over resulted in a 2.3-times increase in the prevalence of T2D, whereas exposure to the PCBs threshold level increased the odds of T2D by 1.4 times compared with the reference group (no exposure). In our earlier findings from Ontario and Manitoba, we found that dietary exposure to $\geq 2.11$ $\mathrm{ng} / \mathrm{kg}$ bw/day of DDE and $\geq 1.47 \mathrm{ng} / \mathrm{kg}$ bw/day of PCBs was associated with a similar increase of T2D by about 2.3 times for DDE and 1.4 times for PCBs, respectively (Marushka et al. 2018).

Our findings on positive associations between POPs and $\mathrm{T} 2 \mathrm{D}$ are in agreement with other epidemiological studies, using cross-sectional design (Everett and Thompson 2012; Lee et al. 2006; Philibert et al. 2009; Singh and Chan 2017; Zuk et al. 2019), and prospective cohort or case-control design (Lee et al. 2011; Raffetti et al. 2018; Tornevi et al. 2019; Wolf et al. 2019; Wu et al. 2013; Zong et al. 2018). However, ORs from the cross-sectional analyses were slightly higher than those from the prospective assessments, which were explained by potential changes in weight and other lifestyle factors among T2D cases (Tornevi et al. 2019).

The risk of diabetes with POPs exposure has also been reported among some Indigenous populations. Among the Mohawk Nation of Akwesasne (located in southern Ontario), positive associations between elevated serum concentrations of PCBs $(\mathrm{OR}=3.3)$ and $\mathrm{DDE}(\mathrm{OR}=6.4)$ with diabetes prevalence were observed in a cross-sectional study among adults ( $\geq 30$ years) (Codru et al. 2007). Positive associations between DDE and PCBs with the prevalence of diabetes and fasting glucose were reported among the Inuit in Canada (Singh and Chan 2017). Positive dose-response 
Table 5 Multiple logistic regression analyses of fish consumption and type 2 diabetes $(n=6091)$

\begin{tabular}{|c|c|c|c|c|}
\hline & $\begin{array}{l}\text { No fish } \\
\text { Reference }\end{array}$ & $\begin{array}{l}<10 \text { g/day } \\
\text { OR }(95 \% \text { CI) }\end{array}$ & $\begin{array}{l}10-20 \mathrm{~g} / \text { day } \\
\text { OR }(95 \% \mathrm{CI})\end{array}$ & $\begin{array}{l}>20 \mathrm{~g} / \text { day } \\
\text { OR }(95 \% \mathrm{CI})\end{array}$ \\
\hline \multicolumn{5}{|c|}{ Total population } \\
\hline Model 1 & 1.0 & $1.16(0.89-1.52)$ & $1.49 * *(1.03-2.14)$ & $1.74 * *(1.21-2.51)$ \\
\hline Model 2 & 1.0 & $1.15(0.88-1.51)$ & $1.46 *(0.99-2.15)$ & $1.78 * * *(1.20-2.66)$ \\
\hline \multicolumn{5}{|l|}{ Females } \\
\hline Model 1 & 1.0 & $1.43 * *(1.06-1.90)$ & $1.46(0.78-2.73)$ & $2.12 * * *(1.38-3.27)$ \\
\hline Model 2 & 1.0 & $1.36^{* *}(1.02-1.81)$ & $1.43(0.77-2.66)$ & $2.08 * * *(1.31-3.31)$ \\
\hline \multicolumn{5}{|l|}{ Males } \\
\hline Model 1 & 1.0 & $0.72(0.45-1.17)$ & $1.22(0.65-2.28)$ & $1.12(0.56-2.21)$ \\
\hline Model 2 & 1.0 & $0.73(0.45-1.20)$ & $1.29(0.65-2.57)$ & $1.25(0.63-2.48)$ \\
\hline \multicolumn{5}{|l|}{ Aged $<45 \mathrm{y}$} \\
\hline Model 1 & 1.0 & $1.27(0.81-1.98)$ & $0.70(0.30-1.59)$ & $2.61 * *(1.02-6.62)$ \\
\hline Model 2 & 1.0 & $1.27(0.79-2.02)$ & $0.74(0.31-1.78)$ & $2.65 * *(1.01-6.96)$ \\
\hline \multicolumn{5}{|l|}{ Aged $\geq 45 y$} \\
\hline Model 1 & 1.0 & $1.09(0.81-1.47)$ & $1.83 * *(1.08-3.09)$ & $1.50 * *(1.04-2.18)$ \\
\hline Model 2 & 1.0 & $1.06(0.79-1.43)$ & $1.78 * *(1.03-3.11)$ & $1.48 * *(1.01-2.15)$ \\
\hline
\end{tabular}

${ }^{*} p<0.1,{ }^{* *} p<0.05,{ }^{* * *} p<0.01 ; O R$, odds ratio

Model 1: adjusted for age, gender, body mass index, ecozone and region

Model 2: model 1 additionally adjusted for physical activity, smoking, energy intake, dieting status, years of education, household size, income source and employment status associations between POPs and diabetes were found in two Indigenous populations in Quebec (Cordier et al. 2020). A study among Oji-Cree First Nation in Northwestern Ontario examined the associations among self-reported diabetes, fish

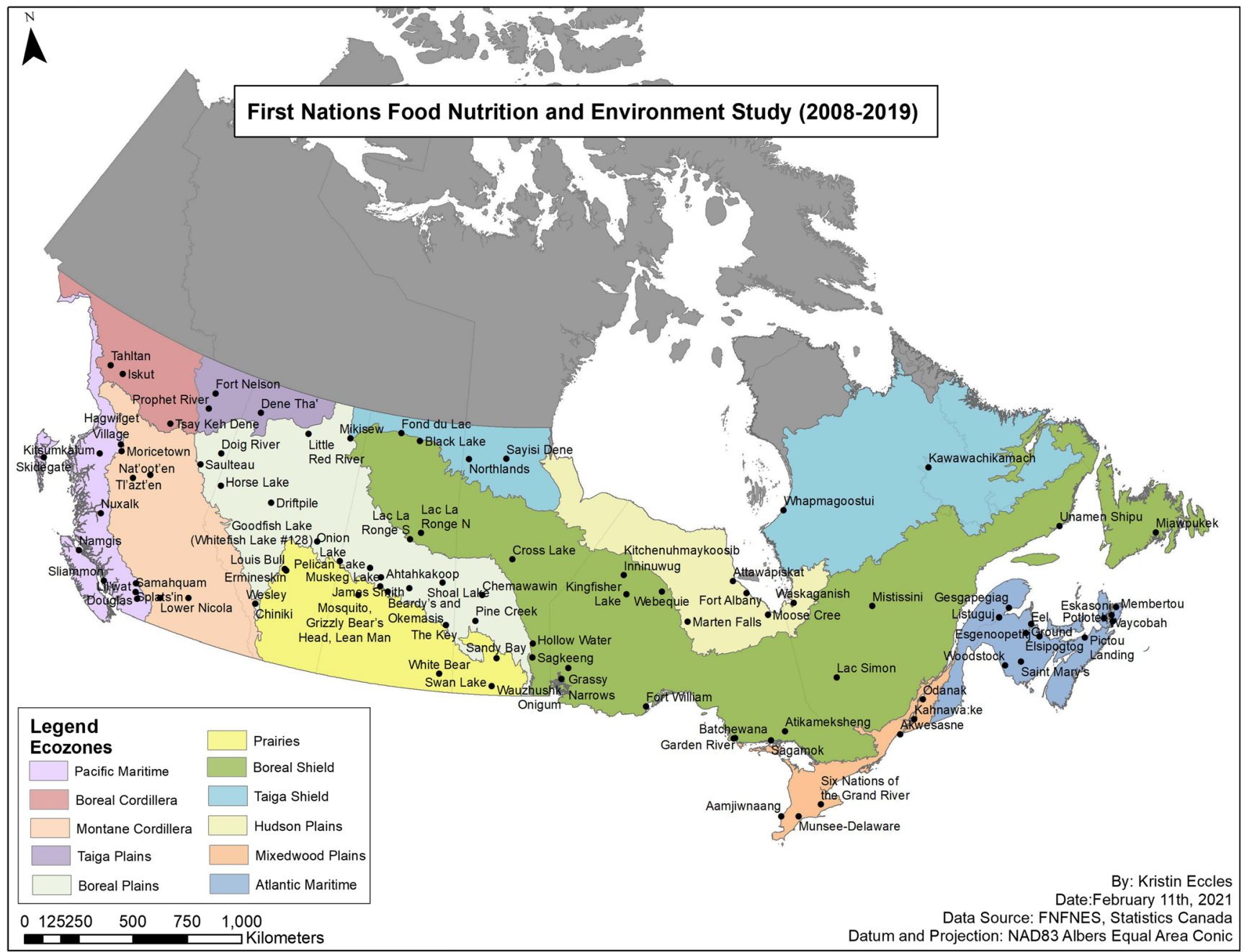

Fig. 1 Map of participating First Nations communities across eleven ecozones in Canada 
consumption and serum DDE and PCBs levels. This study reported that exposure to elevated DDE and PCBs was associated with an increased risk of diabetes, whereas consumption of fish, particularly trout and whitefish, showed protective effects (Philibert et al. 2009). Zuk et al. (2019) examined the association between environmental contaminant mixtures and the prevalence of T2D among Eeyou First Nations and found that positive DDT loadings were associated with T2D with a prevalence ratio of 1.27 (95\% CI: 1.02-1.60) (Zuk et al. 2019).

It is important to note that the majority of previous epidemiological research investigated blood levels of POPs in relation to T2D, whereas we assessed the effects of dietary POPs intake through the consumption of locally caught fish. However, since exposure to POPs occurs primarily through fish consumption (Fitzgerald et al. 1999; Philibert et al. 2009; Seabert et al. 2014), dietary POP intake from fish is considered a reliable indicator of the exposure. Results of the contaminant exposure assessment of the FNFNES also showed that fish was the main source of DDE and PCBs (Chan et al. 2021b).

We found that stronger positive associations between DDE/PCBs exposure and T2D prevalence were among females and older individuals as compared with males and the younger age group. These findings are consistent with previous studies (Wang et al. 2008; Wolf et al. 2019). Gender differences in the associations between DDE/PCBs exposure and T2D may originate from differences in the body fat composition between females and males (Wahlang 2018). Females tend to have a higher proportion of body fat, which serves as a storage site for lipophilic POPs. However, this needs further investigation. Also, POPs are known as endocrine-disrupting chemicals, which can interfere with the activity of estrogen hormones involved in glucose homeostasis and lipid metabolism (Neel and Sargis 2011).

The underlying mechanisms linking organochlorine pesticides and PCBs with T2D are not fully elucidated. However, several hypotheses have been proposed to explain POP effects on the development of T2D. First, POPs are well-known endocrinedisrupting chemicals that can interfere with estrogen hormones, alter glucose homeostasis and impair cellular insulin action (Lee et al. 2018). Second, low POP exposure can also induce mitochondrial dysfunction and reduce oxidative phosphorylation capacities. Mitochondrial dysfunction is known to play a significant role in chronic low-grade inflammation resulting in ectopic fat accumulation in the liver, muscle and pancreas. Low-grade inflammation, in turn, in adipose tissue promotes the development of insulin resistance. In addition, DL-PCBs can bind to the aryl hydrocarbon receptor and thus inhibit insulin secretion by $\beta$-cells, glucose uptake, and functions of insulin in adipose tissue, liver and pancreas (Lee et al. 2018).

Previous studies investigating the relationship between fish consumption and T2D reported that fish and EPA-DHA intake might prevent insulin resistance and glucose tolerance, reduce the levels of inflammatory markers, and improve blood lipid profile (Ebbesson et al. 2005; Liaset et al. 2019; Paquet et al. 2013; Marushka et al. 2017b). Nevertheless, results from systematic review and meta-analyses are inconsistent (Liaset et al. 2019; Telle-Hansen et al. 2019). Growing evidence suggests that the associations between fish consumption and T2D are influenced by the interactions between the levels of toxic chemicals and beneficial nutrients present in fish (Christensen et al. 2016; Lee and Jacobs 2010; Marushka et al. 2018; Wallin et al. 2017). That the positive association between fish as well as dietary DDE/PCBs intake and T2D was observed in the total population and older individuals and was stronger in females suggests that DDE/PCBs concentrations present in fish were the main drivers for the relationship. Furthermore, the associations between DDE/PCBs with T2D were stronger in the models additionally adjusted for EPA-DHA and MeHg intake. This supports our previous findings that elevated levels of DDE/PCBs may diminish the beneficial effects of EPADHA on T2D, while relatively high EPA-DHA intake may attenuate the detrimental effects of DDE/PCBs on T2D (Marushka et al. 2018). On the other hand, the co-exposure to $\mathrm{MeHg}$ can potentially increase the risk of T2D, particularly among females. The relationship between $\mathrm{MeHg}$ exposure and T2D is relatively less studied; more prospective studies are warranted to establish a causal relationship between mercury exposure and the risk of T2D (Roy et al. 2017).

There were differences in the magnitude of the associations between fish and T2D among the younger and older age groups. This may be partially explained by differences in the distribution of males and females in the two age groups. Also, younger individuals consumed less fish ( $11.6 \mathrm{~g} /$ day) than older respondents ( $19.5 \mathrm{~g} /$ day) and consequently have a lower intake of beneficial EPA-DHA. The protective effect of EPADHA in older individuals may partly outweigh the detrimental effects of DDE/PCBs.

Previous risk assessment for dietary exposure to PCBs and DDE using the toxicological reference values (TRVs) of $0.13 \mu \mathrm{g} / \mathrm{kg} /$ day for the sum of non-dioxin-like PCBs by Health Canada (Health Canada 2010) and $10 \mu \mathrm{g} / \mathrm{kg} /$ day for DDT established by the FAO/WHO (WHO 2000) found that the health risk was negligible (Chan et al. 2021b). The breakpoints that we used in this study $(1.47 \mathrm{ng} / \mathrm{kg}$ bw for PCBs and $2.11 \mathrm{ng} / \mathrm{kg}$ bw for DDE) were two to three orders of magnitude lower. These may be due to the identification of POPs being endocrine-disrupting chemicals, which can exhibit harmful effects on the hormone regulation at much lower doses than previously reported (Birnbaum 2012). These results suggest that the health risk of $\mathrm{PCBs} / \mathrm{DDE}$ exposure may have been underestimated. With increasing evidence in the association between POPs exposure and T2D, regulatory agencies may need to review and update the TRVs.

We found notable geographical differences in DDE/ PCBs exposure patterns across ecozones, which reflect 
the distribution and diversity of fish species, the amount of fish consumed, as well as DDE and PCBs concentrations in fish. It would be interesting to perform ecozonebased analyses in order to identify ecozones where fish consumption is positively associated with T2D; however, small sample sizes in some ecozones do not allow the multivariate regression analyses by ecozone.

Detailed results on the concentrations of PCBs and DDE in the species that are the top contributors to the dietary intake by ecozone are reported in Chan et al. (2019, 2021b). Elevated PCBs and DDE are typically found in fish that have high-fat content and/or are at higher trophic levels. In the ecozones where DDE or PCBs intake was higher, such as the Pacific Maritime, Hudson Plains, Mixedwood Plains, Boreal Shield and Taiga Shield, more detailed monitoring programs for PCBs and DDE in fish are needed to ensure that fish consumption does not increase the risk of T2D in the First Nations.

Our study has several strengths. First, the sample is large and regionally representative of all First Nations living onreserve south of the $60^{\text {th }}$ parallel across different regions and ecozones in Canada. Second, the concentrations of DDE, PCBs and $\mathrm{MeHg}$ were measured in locally harvested fish in this study, which allowed accurate estimation of DDE, PCBs and $\mathrm{MeHg}$ intake by using community-specific data on contaminant content in fish species. Third, information on EPADHA levels in fish, derived from the Canadian Nutrient File (Health Canada 2015), captured cooking methods (baked or broiled, smoked, or raw). Also, our results were adjusted for several dietary and lifestyle risk factors for T2D, along with socio-demographic variables and dietary $\mathrm{MeHg}$ exposure. Finally, this study found a strong dose-response relationship among dietary DDE/PCBs, fish intake and T2D. Dietary exposure information is more useful to develop fish consumption advisories.

There are some limitations to this study. First, the crosssectional design does not allow establishing a causal relationship between dietary DDE/PCBs intake and T2D since potential reverse causality is also possible. Therefore, we performed several sensitivity analyses to examine whether individuals diagnosed with $\mathrm{T} 2 \mathrm{D}$ tend to change their diets and lifestyles (described elsewhere: Marushka et al. 2018; Marushka et al. $2017 \mathrm{a}, \mathrm{b}$ ). Specifically, we compared the dietary intake (e.g., energy intake, total fat, saturated fat, protein, carbohydrate, fruit and vegetables, and fish consumption) and lifestyle habits (physical activity, smoking status and dieting status) between participants recently diagnosed with T2D ( $0-5$ years) and individuals who had had T2D for a longer period of time ( $>5$ years). The results showed that there were no statistically significant differences in dietary and lifestyle characteristics between the two groups. In addition, we assessed differences in dietary intake and lifestyle behaviour in participants with and without T2D associated with self-reported dieting status. We found that intakes of fish, dietary n-3 FAs, macronutrients and POP, as well as physical activity, were comparable between the two groups. The results showed that individuals with T2D did not change their diet and lifestyle practices following their diagnosis.

Second, there may be errors associated with our classification of T2D. Generally, there is evidence that First Nations have fewer diagnostic tests and more limited access to healthcare due to various factors such as the remoteness of the First Nations, colonialism and racism (NCCAH 2011; Allen et al. 2020). Therefore, the prevalence of T2D could have been underreported. We compared our estimated T2D prevalence with those reported by the First Nations Regional Health Survey (RHS) Phase 2 (2008-2010) and Phase 3 (2015-2016) (FNIGC 2018, 2012). Overall, the prevalence of diabetes was 20.7\% in 2008-2010 and 19.2\% in 2015-2016 (FNIGC 2018, 2012), which were in a similar range but slightly higher than our estimates $(18.8 \%)$. These results suggest that the relationship observed between exposures to POPs as a risk factor for T2D is likely to be underestimated. Finally, there is a potential for misclassification of exposure due to dietary measurement errors.

Since this study could only be conducted when all the data were collected, the results could not be communicated to each participating community individually. We communicated the highlights of the results at a national closing workshop held in Ottawa in November 2019 (Chan et al. 2021a). This closing workshop, the First Nations Food, Nutrition and Environment Forum, was attended by 275 delegates from 140 First Nations, including 60 of the participating First Nations. More dialogue on the implications of the results and discussion on possible interventions with the participating First Nations are needed.

\section{Conclusion}

This study confirmed our previous findings that dietary DDE/ PCBs exposure might increase the risk of T2D. The associations between dietary DDE/PCBs intake and T2D prevalence were stronger among females and older individuals as compared with males and younger participants. DDE and PCBs exposure patterns significantly varied across Canadian ecozones.

The findings of this study suggest that the effect of DDE/PCBs from fish consumption is driven by geographical differences in DDE/PCBs concentrations in fish species and by the amount of fish consumed, and is more prominent in females than in males. Fish consumption advisories should be tailored to reflect regional and ecozone differences. The research team is collaborating with First Nation partners and health authorities in knowledge translation and risk management. We advocate that Indigenous health research needs to respect diversity, recognize distinct languages and cultures, and promote individual and community self-determination. We hope that the partnership of this research has built local capacity, and the results will help bring about meaningful positive change for the health of people and the environment. 


\section{Appendix}

Table 6 Fish intake and dietary DDE and PCBs exposure by ecozone*

\begin{tabular}{|c|c|c|c|c|c|c|c|c|c|c|c|c|}
\hline \multirow[t]{2}{*}{ Ecozone } & \multicolumn{4}{|c|}{ Fish (g/day) } & \multicolumn{4}{|c|}{ DDE (ng/kg/day) } & \multicolumn{4}{|c|}{ PCBs (ng/kg/day) } \\
\hline & Mean & Median & IQR & $\%$ consumers & Mean & Median & IQR & $\%>2.11$ & Mean & Median & IQR & $\%>1.47$ \\
\hline Pacific Maritime & 76.5 & 45.4 & $20.2-101.2$ & 97.2 & 2.01 & 1.21 & $0.43-2.64$ & 29.8 & 0.75 & 0.32 & $0.09-0.84$ & 14.5 \\
\hline Montane Cordillera & 30.0 & 8.7 & $2.9-28.9$ & 92.5 & 1.05 & 0.31 & $0.09-1.06$ & 16.1 & 0.36 & 0.07 & $0.01-0.27$ & 5.4 \\
\hline Taiga Plains & 13.3 & 1.6 & $0-15.2$ & 66.5 & 0.27 & 0.02 & $0-0.21$ & 2.6 & 0.26 & 0.004 & 0-0.09 & 5.9 \\
\hline Boreal Plains & 6.5 & 1.0 & $0-5.2$ & 61.7 & 0.12 & 0.001 & $0-0.04$ & 1.2 & 0.13 & 0.001 & $0-0.02$ & 1.3 \\
\hline Prairies & 3.6 & 0.1 & $0-1.6$ & 41.8 & 0.05 & 0.001 & $0-0.003$ & 0.4 & 0.10 & 0.001 & $0-0.001$ & 1.7 \\
\hline Boreal Shield & 22.6 & 6.6 & $1.9-21.9$ & 87.1 & 0.54 & 0.11 & $0.01-0.41$ & 6.0 & 1.25 & 0.23 & $0.004-0.98$ & 18.7 \\
\hline Taiga Shield & 22.6 & 8.9 & $2.7-24.6$ & 92.3 & 0.90 & 0.22 & $0.05-0.90$ & 14.3 & 0.96 & 0.26 & $0.07-0.91$ & 18.0 \\
\hline Hudson Plains & 11.2 & 3.4 & $1.01-11.7$ & 82.3 & 0.83 & 0.06 & $0.01-0.38$ & 11.5 & 2.61 & 0.11 & $0.01-1.12$ & 23.3 \\
\hline Mixedwood Plains & 4.3 & 0.3 & $0-3.3$ & 51.0 & 0.44 & 0.01 & $0-0.14$ & 4.1 & 2.24 & 0.002 & $0-0.86$ & 20.0 \\
\hline Atlantic Maritime & 10.1 & 2.7 & $0-10.4$ & 70.6 & 0.20 & 0.04 & $0-0.20$ & 1.0 & 0.33 & 0.06 & $0-0.30$ & 5.7 \\
\hline
\end{tabular}

$I Q R$, interquartile range (e.g., 25th and 75th percentiles); $D D E$, dichlorodiphenyldichloroethylene; $P C B$ s, polychlorinated biphenyls

$2.11 \mathrm{ng} / \mathrm{kg}$ bw/day and $1.47 \mathrm{ng} / \mathrm{kg}$ bw/day are breakpoints for dietary DDE and PCBs intake, respectively (see Marushka et al. (2018) for more details)

* Since diabetes data were not available for Boreal Cordillera, fish and dietary POP exposure in the Boreal Cordillera ecozone are not presented

Unweighted estimates

Acknowledgements The authors would like to acknowledge the efforts of these individuals in the collection of the data used in this study: Olivier Receveur, William David, Laverne Gervais, Lisa Wabegijig, Judy Mitchell, Kathleen Lindhorst and Lynn Barwin. The authors would like to thank all members of the First Nations who participated and worked on the FNFNES study.

Code availability Analysis codes can be shared upon reasonable request.

Author contributions All authors contributed to the study conception and design and data collection. Material preparation and data analysis were performed by Lesya Marushka, Xuefeng Hu and Amy Ing. The first draft of the manuscript was written by Lesya Marushka and all authors commented on previous versions of the manuscript. All authors read and approved the final manuscript.

Funding The data used in this article originate from the FNFNES which was funded by the First Nations and Inuit Health Branch of Indigenous Services Canada. Part of knowledge translation activities was funded by the Canadian Institutes of Health Research. HMC and MB are supported by the Canada Research Chair Program.

Data availability Data are owned by each participating community. The Assembly of First Nations is data custodian and any requests will be addressed to AFN through the corresponding author.

\section{Declarations}

Consent for publication Not applicable.

Conflict of interest The authors declare no conflict of interest.
Open Access This article is licensed under a Creative Commons Attribution 4.0 International License, which permits use, sharing, adaptation, distribution and reproduction in any medium or format, as long as you give appropriate credit to the original author(s) and the source, provide a link to the Creative Commons licence, and indicate if changes were made. The images or other third party material in this article are included in the article's Creative Commons licence, unless indicated otherwise in a credit line to the material. If material is not included in the article's Creative Commons licence and your intended use is not permitted by statutory regulation or exceeds the permitted use, you will need to obtain permission directly from the copyright holder. To view a copy of this licence, visit http://creativecommons.org/licenses/by/4.0/.

\section{References}

Acton, K. J., Ríos Burrows, N., Moore, K., Querec, L., Geiss, L. S., \& Engelgau, M. M. (2002). Trends in diabetes prevalence among American Indian and Alaska Native children, adolescents, and young adults. American Journal of Public Health, 92, 1485-1490. https://doi.org/10.2105/AJPH.92.9.1485.

Allen, L., Hatala, A., Ijaz, S., Courchene, D., \& Bushie, B. (2020). Indigenous-led health care partnerships in Canada. CMAJ, 192(9), E208-E216.

Batal, M., \& Decelles, S. (2019). A scoping review of obesity among Indigenous Peoples in Canada. Journal of Obesity, 2019, 9741090. https://doi.org/10.1155/2019/9741090.

Batal, M., Chan, H. M., Fediuk, K., Ing, A., Berti, P., Sadik, T., \& Johnson-Down, L. (2021a). Associations of health status and diabetes among First Nations Peoples living on-reserve in Canada. Canadian Journal of Public Health, 112(Supplement 1). https:// doi.org/10.17269/s41997-021-00488-6. 
Batal, M., Chan, H. M., Fediuk, K., Ing, A., Berti, P., Sadik, T., \& Johnson-Down, L. (2021b). Importance of the traditional food systems for First Nations adults living on reserves in Canada. Canadian Journal of Public Health, 112(Supplement 1). https://doi.org/10. 17269/s41997-020-00353-y.

Birnbaum, L. S. (2012). Environmental chemicals: evaluating low-dose effects. Environmental Health Perspectives, 120(4), A143-A144. https://doi.org/10.1289/ehp.1205179.

Chan, L., Receveur, O., Sharp, D., Schwartz, H., Ing, A., \& Tikhonov, C. (2011). First Nations Food, Nutrition and Environment Study (FNFNES): Results from British Columbia (2008/2009). Prince George: University of Northern British Columbia, Print.

Chan, L., Batal, M., Sadik, T., Tikhonov, C., Schwartz, H., Fediuk, K., Ing, A., Marushka, L., Lindhorst, K., Barwin, L., Berti, P., Singh, K., Receveur, O. (2019). FNFNES final report for eight Assembly of First Nations regions: draft comprehensive technical report.

Chan, H. M., Fediuk, K., Batal, M., Sadik, T., Tikhonov, C., Ing, A., \& Barwin, L. (2021a). The First Nations Food, Nutrition and Environment Study (2008-2018) - rationale, design, methods and lessons learned. Canadian Journal of Public Health, 112(Supplement 1). https://doi.org/10.17269/s41997-021-00480-0.

Chan, H. M., Singh, K., Batal, M., Maruska, L., Tikhonov, C., Sadik, T., Schwartz, H., Ing, A., \& Fediuk, K. (2021b). Levels of metals and persistent organic pollutants in traditional foods consumed by First Nations living on-reserve in Canada. Canadian Journal of Public Health, 112(Supplement 1). https://doi.org/10.17269/s41997-02100495-7.

Christensen, K. Y., Thompson, B. A., Werner, M., Malecki, K., Imm, P., \& Anderson, H. A. (2016). Levels of persistent contaminants in relation to fish consumption among older male anglers in Wisconsin. International Journal of Hygiene and Environmental Health, 219, 184-194. https://doi.org/10.1016/j.ijheh.2015.11.001.

Codru, N., Schymura, M. J., Negoita, S., Rej, R., \& Carpenter, D. O. (2007). Diabetes in relation to serum levels of polychlorinated biphenyls and chlorinated pesticides in adult native Americans. Environmental Health Perspectives, 115, 1442-1447. https://doi. org/10.1289/ehp.10315.

Cordier, S., Anassour-laouan-sidi, E., Lemire, M., Costet, N., Lucas, M., \& Ayotte, P. (2020). Association between exposure to persistent organic pollutants and mercury, and glucose metabolism in two Canadian Indigenous populations. Environmental Research, 184, 109345. https://doi.org/10.1016/j.envres.2020.109345.

Crowshoe, L., Dannenbaum, D., Green, M., Henderson, R., Naqshbandi Hayward, M., \& Toth, E. (2018). Diabetes Canada 2018 clinical practice guidelines for the prevention and management of diabetes in Canada: type 2 diabetes and Indigenous Peoples. Canadian Journal of Diabetes, 42, S296-S306. https://doi.org/10.1016/j.jcjd.2017.10.022.

Day, C., \& Bailey, C. J. (2011). Obesity in the pathogenesis of type 2 diabetes. British Journal of Diabetes and Vascular Disease, 11, 55 61. https://doi.org/10.1177/1474651411407418.

Ebbesson, S. O. E., Risica, P. M., \& Ebbesson, L. O. E. E. A. (2005). Omega-3 fatty acids improve glucose tolerance and components of the metabolic syndrome in Alaskan Eskimos. International Journal of Circumpolar Health, 64, 396-408.

Everett, C. J., \& Thompson, O. M. (2012). Associations of dioxins, furans and dioxin-like PCBs with diabetes and pre-diabetes: Is the toxic equivalency approach useful? Environmental Research, 118, 107111. https://doi.org/10.1016/j.envres.2012.06.012.

Fedor, D., \& Kelley, D. S. (2009). Prevention of insulin resistance by n-3 polyunsaturated fatty acids. Current Opinion in Clinical Nutrition and Metabolic Care, 12, 138-146. https://doi.org/10.1097/MCO. 0b013e3283218299.

Fitzgerald, E. F., Deres, D. A., Hwang, S. A., Bush, B., Yang, B. Z., Tarbell, A., \& Jacobs, A. (1999). Local fish consumption and serum PCB concentrations among Mohawk men at Akwesasne. Environmental Research, 80, S97-S103. https://doi.org/10.1006/enrs.1998.3908.
FNIGC. (2012). First Nations Regional Health Survey (RHS) 2008/10: national report on youth living in First Nations Communities. Ottawa: FNIGC.

FNIGC. (2018). National Report of the First Nations Regional Health Survey. Phase 3 (Vol. 1). Ottawa: FNIGC.

He, K., Xun, P., Liu, K., \& Morris, S. (2013). Mercury exposure in young adulthood and incidence of diabetes later in life (Vol. 36). https:// doi.org/10.2337/dc12-1842.

Health Canada. (2010). Federal contaminated site risk assessment in Canada, Part II: Health Canada Toxicological Reference Values (TRVs) and Chemical-Specific Factors, Version 2.0.

Health Canada. (2015). Canadian Nutrient File (CNF) [WWW Document]. https://food-nutrition.canada.ca/cnf-fce/index-eng.jsp.

Johnson-Down, L., Labonte, M. E., Martin, I. D., Tsuji, L. J., Nieboer, E., Dewailly, E., Egeland, G., \& Lucas, M. (2015). Quality of diet is associated with insulin resistance in the Cree (Eeyouch) indigenous population of northern Québec. Nutrition, Metabolism, and Cardiovascular Diseases, 25(1), 85-92. https://doi.org/10.1016/j. numecd.2014.08.002 Epub 2014 Aug 28.

Kuhnlein, V., \& Chan, H. (2000). Environment and contaminants in traditional food systems of Northern Indigenous Peoples (pp. 595-626).

Kuhnlein, H. V., Receveur, O., Soueida, R., \& Egeland, G. M. (2004). Arctic indigenous peoples experience the nutrition transition with changing dietary patterns and obesity. The Journal of Nutrition, 134, 1447-1453.

Lee, D.-H., \& Jacobs, D. R. (2010). Inconsistent epidemiological findings on fish consumption may be indirect evidence of harmful contaminants in fish. Journal of Epidemiology and Community Health, 64, 190-192. https://doi.org/10.1136/jech.2009.093328.

Lee, D.-H., Lee, I.-K., Song, K., Steffes, M., Toscano, W., Baker, B. A., \& Jacobs, D. R. (2006). A strong dose-response relation between serum concentrations of persistent organic pollutants and diabetes: results from the National Health and Examination Survey 19992002. Diabetes Care, 29, 1638-1644. https://doi.org/10.2337/ dc06-0543.

Lee, D.-H. H., Steffes, M. W., Sjödin, A., Jones, R. S., Needham, L. L., \& Jacobs, D. R. (2011). Low dose organochlorine pesticides and polychlorinated biphenyls predict obesity, dyslipidemia, and insulin resistance among people free of diabetes. PLoS One, 6, e15977. https://doi.org/10.1371/journal.pone.0015977.

Lee, Y.-M., Jacobs Jr., D. R., \& Lee, D.-H. (2018). Persistent organic pollutants and type 2 diabetes: a critical review of review articles. Frontiers in Endocrinology, 9, 1-9. https://doi.org/10.3389/fendo. 2018.00712.

Liaset, B., Oyen, J., Jacques, H., Kristiansen, K., \& Madsen, L. (2019). Seafood intake and the development of obesity, insulin resistance and type 2 diabetes. Nutrition Research Reviews, 32, 146-167. https://doi.org/10.1017/S0954422418000240.

Marushka, L., Batal, M., David, W., Schwartz, H., Ing, A., Fediuk, K., Sharp, D., Black, A., Tikhonov, C., \& Chan, H. M. (2017a). Association between fish consumption, dietary omega-3 fatty acids and persistent organic pollutants intake, and type 2 diabetes in 18 First Nations in Ontario, Canada. Environmental Research, 156, 725-737. https://doi.org/10.1016/j.envres.2017.04.034.

Marushka, L., Batal, M., Sharp, D., Schwartz, H., Ing, A., Fediuk, K., Black, A., Tikhonov, C., \& Chan, H. M. (2017b). Fish consumption is inversely associated with type 2 diabetes in Manitoba First Nations communities. FACETS, 2, 795-818. https://doi.org/10. 1139/facets-2017-0023.

Marushka, L., Hu, X., Batal, M., Sadik, T., Schwartz, H., Ing, A., Fediuk, K., Tikhonov, C., \& Chan, H. M. (2018). The relationship between persistent organic pollutants exposure and type 2 diabetes among First Nations in Ontario and Manitoba, Canada : A Difference in Difference Analysis. International Journal of Environmental Research and Public Health, 1-19. https://doi.org/10.3390/ijerph15030539. 
Nanri, A., Mizoue, T., Noda, M., Takahashi, Y., Matsushita, Y., \& Poudel-tandukar, K. (2011). Fish intake and type 2 diabetes in Japanese men and women : the Japan Public Health Center - based Prospective Study $1-3$. The American Journal of Clinical Nutrition, 94, 884-891. https://doi.org/10.3945/ajcn.111.012252.1.

National Collaborating Centre for Aboriginal Health (NCCAH). (2011). Access to health services as a social determinant of First Nations, Inuit and Metis health. http://www.nccah-ccnsa.ca.

Neel, B. A., \& Sargis, R. M. (2011). The paradox of progress: environmental disruption of metabolism and the diabetes epidemic. Diabetes, 60, 1838-1848. https://doi.org/10.2337/db11-0153.

Paquet, C., Propsting, S., \& Daniel, M. (2013). Total n-3 fatty acid and SFA intakes in relation to insulin resistance in a Canadian First Nation at risk for the development of type 2 diabetes. Public Health Nutrition, 17, 1337-1341. https://doi.org/10.1017/ S1368980013000542.

Philibert, A., Schwartz, H., \& Mergler, D. (2009). An exploratory study of diabetes in a first nation community with respect to serum concentrations of p,p'-DDE and PCBs and fish consumption. International Journal of Environmental Research and Public Health, 6, 3179-3189. https://doi.org/10.3390/ijerph6123179.

Raffetti, E., Donato, F., Speziani, F., Scarcella, C., Gaia, A., \& Magoni, M. (2018). Polychlorinated biphenyls (PCBs) exposure and cardiovascular, endocrine and metabolic diseases: a population-based cohort study in a North Italian highly polluted area. Environment International, 120, 215-222. https://doi.org/10.1016/j.envint.2018. 08.022

Reeds, J., Mansuri, S., Mamakeesick, M., et al. (2016). Dietary patterns and type 2 diabetes mellitus in a First Nations community. Canadian Journal of Diabetes, 40(4), 304-310.

Roy, C., Tremblay, P., \& Ayotte, P. (2017). Is mercury exposure causing diabetes, metabolic syndrome and insulin resistance? A systematic review of the literature. Environmental Research Journal, 156, 747 760. https://doi.org/10.1016/j.envres.2017.04.038.

Seabert, T. A., Pal, S., Pinet, B. M., Haman, F., Robidoux, M. A., Imbeault, P., Krümmel, E. M., Kimpe, L. E., Blais, J. M., Krommel, E. M., Kimpe, L. E., \& Blais, J. M. (2014). Elevated contaminants contrasted with potential benefits of n-3 fatty acids in wild food consumers of two remote first nations communities in Northern Ontario, Canada. PLoS One, 9, e090351. https://doi.org/ 10.1371/journal.pone.0090351.

Singh, K., \& Chan, H. M. (2017). Persistent organic pollutants and diabetes among Inuit in the Canadian Arctic. Environment International, 101, 183-189. https://doi.org/10.1016/j.envint.2017. 02.002

Statistics Canada. (2018). Health Fact Sheets: Diabetes, 2017, Statistics Canada.

Telle-Hansen, V. H., Gaundal, L., \& Myhrstad, M. C. W. (2019). Polyunsaturated fatty acids and glycemic control in type 2 diabetes. Nutrients, 11, 12-15. https://doi.org/10.3390/nu11051067.

Tikhonov, C., Schwartz, H., Marushka, L., Chan, H. M., Batal, M., Sadik, T., Ing, A., \& Fediuk, K. (2021). Regionally representative hair mercury levels in Canadian First Nations adults living on reserves. Canadian Journal of Public Health, 112(Supplement 1). https://doi. org/10.17269/s41997-021-00508-5.

Tornevi, A., Sommar, J., Rantakokko, P., Åkesson, A., Donat-Vargas, C., Kiviranta, H., Rolandsson, O., Rylander, L., Wennberg, M., \& Bergdahl, I. A. (2019). Chlorinated persistent organic pollutants and type 2 diabetes - a population-based study with pre- and postdiagnostic plasma samples. Environmental Research, 174, 35-45. https://doi.org/10.1016/j.envres.2019.04.017.

Villegas, R., Xiang, Y., Elasy, T., Li, H., Yang, G., Cai, H., Ye, F., Gao, Y., Shyr, Y., \& Zheng, W. (2011). Fish, shellfish, and long-chain n-3 fatty acid consumption and risk of incident type 2 diabetes in middle-aged Chinese men and women. The American Journal of Clinical Nutrition, 94(2), 543-551. https://doi.org/10.3945/ajcn. 111.013193.

Wahlang, B. (2018). Exposure to persistent organic pollutants: Impact on women's health. Reviews on Environmental Health, 33, 331-348. https://doi.org/10.1515/reveh-2018-0018.

Wallin, A., Di Giuseppe, D., Orsini, N., Åkesson, A., Forouhi, N. G., \& Wolk, A. (2017). Fish consumption and frying of fish in relation to type 2 diabetes incidence: a prospective cohort study of Swedish men. European Journal of Nutrition. https://doi.org/10.1007/ s00394-015-1132-6.

Wang, S. L., Tsai, P. C., Yang, C. Y., \& Guo, Y. L. (2008). Increased risk of diabetes and polychlorinated biphenyls and dioxins. A 24-year follow-up study of the Yucheng cohort. Diabetes Care, 31, 1574 1579. https://doi.org/10.2337/dc07-2449.

WHO. (2000). Evaluation of the toxicity of pesticide residues in food. World Health Organization. FAO Meeting Report No. PL/1965/10/ 1 .

Wolf, K., Bongaerts, B. W. C., Schneider, A., Huth, C., Meisinger, C., Peters, A., Schneider, A., Wittsiepe, J., Schramm, K. W., Greiser, K. H., Hartwig, S., Kluttig, A., \& Rathmann, W. (2019). Persistent organic pollutants and the incidence of type 2 diabetes in the CARLA and KORA cohort studies. Environment International, 129, 221-228. https://doi.org/10.1016/j.envint.2019.05.030.

Wu, J. H. Y., Micha, R., Imamura, F., Pan, A., Biggs, M. L., Ajaz, O., Djoussé, L., Hu, F. B., \& Mozaffarian, D. (2012). Omega-3 Fatty acids and incident Type 2 Diabetes: a systematic review and metaanalysis. The British Journal of Nutrition, 107, S214-S227. https:// doi.org/10.1017/S0007114512001602.

Wu, H., Bertrand, K. a., Choi, A. L., Hu, F. B., Laden, F., Grandjean, P., \& Sun, Q. (2013). Persistent organic pollutants and type 2 diabetes: a prospective analysis in the nurses' health study and meta-analysis. Environmental Health Perspectives, 121, 153-161. https://doi.org/ 10.1289/ehp.1205248.

Young, T. K., Reading, J., Elias, B., \& O’Neil, J. D. (2000). Type 2 diabetes mellitus in Canadas First Nations: status of an epidemic in progress. Canadian Medical Association Journal, 163, 561-566.

Zhang, M., Picard-Deland, E., \& Marette, A. (2013). Fish and marine omega-3 polyunsatured fatty acid consumption and incidence of type 2 diabetes: A systematic review and meta-analysis. International Journal of Endocrinology, 2013, 20-22. https://doi. org/10.1155/2013/501015.

Zheng, J.-S., Huang, T., Yang, J., Fu, Y.-Q., \& Li, D. (2012). Marine N-3 polyunsaturated fatty acids are inversely associated with risk of type 2 diabetes in Asians: a systematic review and meta-analysis. PLoS One, 7, e44525. https://doi.org/10.1371/journal.pone.0044525.

Zong, G., Valvi, D., Coull, B., Göen, T., Hu, F. B., Nielsen, F., Grandjean, P., \& Sun, Q. (2018). Persistent organic pollutants and risk of type 2 diabetes: a prospective investigation among middleaged women in Nurses' Health Study II. Environment International, 114, 334-342. https://doi.org/10.1016/j.envint.2017.12.010.

Zuk, A. M., Tsuji, L. J. S., Nieboer, E., Martin, I. D., \& Liberda, E. N. (2019). Examining environmental contaminant mixtures among adults with type 2 diabetes in the Cree First Nation communities of Eeyou Istchee, Canada. Scientific Reports, 9, 1-11. https://doi. org/10.1038/s41598-019-52200-x.

Publisher's note Springer Nature remains neutral with regard to jurisdictional claims in published maps and institutional affiliations. 